\title{
Endocrine dysfunction in children with Shwachman-Diamond syndrome
}

\author{
Agnieszka Bogusz-Wójcik', Honorata Kołodziejczyk², Elżbieta Moszczyńska', Maja Klaudel-Dreszler ${ }^{3}$, \\ Grzegorz Oracz ${ }^{3}$, Joanna Pawłowska ${ }^{3}$, Mieczysław Szalecki ${ }^{1,4}$
}

${ }^{1}$ Department of Endocrinology and Diabetology, The Children's Memorial Health Institute, Warsaw, Poland

${ }^{2}$ Anthropology Department, The Children's Memorial Health Institute, Warsaw, Poland

${ }^{3}$ Department of Gastroenterology, Hepatology, Feeding Disorders and Paediatrics, The Children's Memorial Health Institute, Warsaw, Poland

${ }^{4}$ Collegium Medicum, University of Jan Kochanowski, Kielce, Poland

\begin{abstract}
Introduction: Shwachman-Diamond syndrome (SDS) is a rare autosomal recessive disorder characterized by pancreatic exocrine insufficiency, immune deficiency, bone marrow failure, and bone malformations. Systematic data concerning endocrine function in SDS are limited. We studied patients diagnosed in The Children's Memorial Health Institute in Warsaw, Poland, to assess the prevalence of various endocrinopathies.

Material and methods: In the pilot study, retrospective data were collected for 5 patients with SDS. Subsequently, patients with SDS aged 3-16 years were recruited prospectively. In total, 19 patients with mutations in the SBDS gene were studied. Data were collected on anthropometric measurements, systemic screening tests of pituitary, thyroid, adrenal, pancreatic, and gonadal function, as well as bone mineral density. Descriptive statistics were tabulated and group differences assessed.

Results: Twelve patients (63\%) had $\geq 1$ endocrine disorder, including growth hormone dysfunction (10 patients, 53\%), hypothyroidism (2 patients, $10 \%)$, congenital hypopituitarism (1 patient, $5 \%)$, and/or type 1 diabetes mellitus (T1DM) (1 patient, $5 \%$ ). The group of boys presented with a significantly lower height $(-2.1 \mathrm{SD}, \mathrm{p}<0.0001)$ and BMI $(-1.0 \mathrm{SD}, \mathrm{p}<0.00001)$. The group of girls also showed significantly lower height $(-2.6 \mathrm{SD}, \mathrm{p}<0.00001)$ and BMI $(-0.7 \mathrm{SD}, \mathrm{p}<0.0001)$. All patients had significantly lower height than their mid-parental height. Delayed bone age was found in 15 patients (84\%) and osteopaenia in 12 of 15 patients $(80 \%)$.

Conclusions: Endocrine dysfunctions are common in SDS, especially growth hormone (GH) deficiency. Children with poor growth can benefit from an endocrinological evaluation and tests for GH deficiency. Bone mineral density measurements should be a part of a routine screening. Longitudinal studies are needed to better understand the aetiology and true prevalence of these disorders. (Endokrynol Pol 2021; 72 (3): 211-216)
\end{abstract}

Key words: Shwachman-Diamond syndrome; short stature; growth hormone deficiency; osteopaenia

\section{Introduction}

Shwachman-Diamond syndrome (SDS) is a rare, autosomal recessive disorder characterized by pancreatic exocrine insufficiency, immune deficiency, bone marrow failure, skeletal abnormalities, and predisposition to leukaemia [1]. Patients frequently present failure to thrive, susceptibility to infections, and short stature [2]. Shwachman-Diamond syndrome is a disorder of ribosomal biogenesis, with approximately $90 \%$ of individuals having biallelic mutations in the Shwachman-Bodian-Diamond syndrome gene (SBDS) located on chromosome 7q11 [3]. Currently, mutations in the SRP54, DNAJC21, and EFL1 [4-6] have been reported in disorders sharing clinical feature of SDS [7]. However, a negative genetic test should not exclude the diagnosis. An accurate clinical evaluation is important in order to diagnose the presence of the syndrome [2].Along with the aforementioned characteristics, short stature is recognized as a common feature of SDS [8,9]. Moreover, some patients with SDS have been diagnosed with growth hormone deficiency $[2,8,10,11]$, as well as several with type 1 diabetes mellitus (T1DM) [12-15], adrenal insufficiency, hypopituitarism, hypothyroidism [15], and congenital hypopituitarism [16]. Characterization of the SDS clinical phenotype and endocrine dysfunction remains incomplete.

The aim of our study was to estimate the prevalence of various endocrinopathies in the SDS population. 


\section{Material and methods}

\section{Patients}

We first performed a retrospective chart review of 5 patients diagnosed with SDS and treated in the Endocrine Department of The Children's Memorial Health Institute (CMHI) in Warsaw, Poland between 2005 and 2016. Subsequently, 13 patients diagnosed in CMHI were recruited prospectively from 2017 to 2019. Inclusion criteria included a diagnosis of SDS based on clinical criteria proposed by Dror et al. in 2011 [1], confirmed mutation in the SBDS gene (MEDGEN, Poland), and age between 3 and 17 years.

\section{Study procedures}

The study protocol was consistent with the Declaration of Helsinki and approved by the IRB (33/KBE/2018). Written parental consent was obtained in all cases. Patients were assessed by an endocrinologist for clinical and laboratory endocrine evaluation. Growth hormone $(\mathrm{GH})$ deficiency was observed in 7 patients requiring recombinant human growth hormone $(\mathrm{rGH})$ treatment, but only anthropometric measurements and laboratory samples carried out before rGH substitution therapy were analysed. At 2 years of age, 2 patients underwent haematopoietic stem cell transplantation (HSCT). Data on endocrine screening were collected at the age of 5 and 6 years.

\section{Clinical and anthropometric data}

The endocrinological assessment included data on clinical history and physical examination with pubertal staging. Axiological parameters including body height, weight, and body mass index (BMI) $\left(\mathrm{w} / \mathrm{h}^{2} ; \mathrm{w}=\right.$ weight $[\mathrm{kg}], \mathrm{h}=$ hight $\left.[\mathrm{m}]\right)$ were collected from all patients and their parents following standard protocol. Measurements were performed at the Department of Anthropology, CMHI. Data were standardized and referred to the average values of the population of healthy Polish children [17], expressed as standard deviation score (SD) separately for girls and boys, according to the following formula:

\section{Standard deviation score $=(X$ examined $-X$ population $) /$} ISD of the population.

Short stature was defined as height below -2.0 SD for age and gender. Parental heights were used to calculate mid-parental height (MPH). Bone age was analysed using the Greulich and Pyle method.

\section{Biochemical testing}

Endocrine test results were collected and compared with ageappropriate reference ranges established in the clinical laboratory of CMHI. Laboratory testing was systematically performed between 07:00 and 08:00 AM after an overnight fast. Glucose regulation was considered abnormal if fasting glucose was $\geq 100 \mathrm{mg} / \mathrm{dL}$, glucose in 2-hour oral glucose tolerance test (OGTT) was $\geq 140 \mathrm{mg} / \mathrm{dL}$, or haemoglobin $\mathrm{A}_{1 \mathrm{c}}\left(\mathrm{HbA}_{1 c}\right)$ (high-pressure liquid chromatography) was $>6.0 \%$. Postprandial insulin (chemiluminescent immunoassay) was considered elevated if $>80 \mathrm{mIU} / \mathrm{mL}$ on $120^{\prime}$ OGTT.

All patients with height $<-2 \mathrm{SD}$ below mean were evaluated for GH deficiency. GH deficiency was diagnosed if stimulated peak of GH on 2 standard stimulation tests (with clonidine, glucagon, and/or arginine) were $<10 \mathrm{ng} / \mathrm{mL}$.

Additionally, all patients had undergone insulin-like growth factor 1 (IGF-1) (radioimmunoassay), insulin-like growth factor-binding protein 3 (IGFBP-3) (chemiluminescent immunoassay), thyroidstimulating hormone (TSH) (microparticle enzyme immunoassay), and free thyroxine (FT4) (equilibrium dialysis) measurements. Puberty was considered delayed if boys had no signs of pubertal maturation by age 14 years, or girls had no breast development by age 13 years. Follicle stimulating hormone (FSH) and luteinizing hormone (LH) were measured by immunochromatographic membrane assay (ICMA), and steroid hormones by liquid chromatography followed by tandem mass spectrometry (LC-MS/MS). Serum $25(\mathrm{OH}) \mathrm{D}$ levels were interpreted as sufficient $(>30-50$ $\mathrm{ng} / \mathrm{mL})$, insufficient $(20-30 \mathrm{ng} / \mathrm{mL})$, or deficient $(<20 \mathrm{ng} / \mathrm{mL})$ [18]. Pancreatic insufficiency was defined as faecal fat quantities of $>5$ g/day. 72-hour faecal fat quantification using the modified van de Kamer method remains the gold standard for diagnosing EPI with fat maldigestion. In this method samples were pooled over a 3-day period while consuming a normal diet. Enzyme replacement therapy, if implemented, was withheld 7 days before stool collection. In patients who had more than 1 test, the highest result was taken into consideration [19].

Bone mineral density (BMD) of the lumbar spine (L1-L4) and whole body were measured with dual-energy X-ray absorptiometry (DXA, Hologic Discovery A $®$, Bedford, USA). According to the WHO classification [20] osteopaenia was defined as T-score from $<-1.0$ to -2.5 and osteoporosis as T-score $<-2.5$.

\section{Statistical analysis}

Statistical analysis was performed using Statistica 7.0. (StatSoft, INC). Results were expressed as median (range) and frequencies for categorical variables. The Fisher test was used for comparison of different groups for categorical variables. Student's t-test was used to assess anthropometric parameters. $p<0.05$ was considered statistically significant.

\section{Results}

\section{Patients' characteristics}

Nineteen (13 girls/ 6 boys, age range 3.5-16.2 years) patients diagnosed with SDS were recruited to our study (Tab. 1 and 2). All patients were of Caucasian and Polish origin with a median age at diagnosis of 2.7 years (range: 0.1-12.5 years). The median gestational age was 39 weeks (range: $33-41$ weeks), and the median weight at birth was $-1.2 \mathrm{SD}$ (ranging from -1.9 to $+0.7 \mathrm{SD}$ ) in the group of boys and $-0.7 \mathrm{SD}$ (ranging from -1.7 to +1.5 $\mathrm{SD})$ in the girls. Pancreatic insufficiency was observed

Table 1. Patients' characteristics

\begin{tabular}{lcc}
\hline \multirow{2}{*}{ Patients' characteristics } & \multicolumn{2}{c}{ Study cohort } \\
\cline { 2 - 3 } & Male & Female \\
\hline Total & 6 & 13 \\
\hline Gestational age [weeks] & $39[38-40]$ & $39[33-41]$ \\
\hline Preterm & 0 & $2(15)$ \\
\hline Weight at birth [SD] & $-1.3[-1.9-0.7]$ & $-0.8[-1.7-1.5]$ \\
\hline Length at birth [SD] & $-1.5[-1.7--0.6]$ & $-1.1[-1.7-0.1]$ \\
\hline Age at diagnosis [years] & $1.4[0.1-3.5]$ & $3.1[0.1-12.5]$ \\
\hline Pancreatic insufficiency & $5(83)$ & $11(84)$ \\
\hline Neutropaenia & $6(100)$ & $12(92)$ \\
\hline Heart problems & 0 & $1(7)$ \\
\hline Skeletal abnormalities & $6(100)$ & $13(100)$ \\
\hline $\begin{array}{l}\text { Hematopoietic stem cell } \\
\text { transplantation }\end{array}$ & 0 & $2(15)$ \\
\hline
\end{tabular}

SD — standard deviation score; values are $\mathrm{n}, \mathrm{n}(\%)$ or median [range]. The percentage is given in brackets and refers to the total count of male and female patients 
Table 2. Clinical characteristics of patients with Shwachman-Diamond syndrome (SDS) by sex

\begin{tabular}{lcc}
\hline \multirow{2}{*}{ Patients' characteristics } & \multicolumn{2}{c}{ Mtudy cohort } \\
\cline { 2 - 3 } & 6 & Female \\
\hline Total & $6.9[3.5-12.4]$ & $6.8[3.7-13.2]$ \\
\hline $\begin{array}{l}\text { Age at endocrine evaluation } \\
\text { lyears] }\end{array}$ & $-2.1[-3.6-$ & $-2.6[-5.3-$ \\
\hline Height [SD] & $-1.8]^{*}$ & $-0.8]^{*}$ \\
\hline Mid-parental height [SD] & $0.1[-1.3-1.4]$ & $-0.1[-1.5-1.3]$ \\
\hline BMI [SD] & $-1.0[-1.5-0.5]^{*}$ & $-0.7[-1.7-1.9]^{*}$ \\
\hline $\begin{array}{l}\text { Difference between } \\
\text { subject's height [SD] } \\
\text { and MPH [SD] }\end{array}$ & $-2.2[-3.2-$ & $-2.5[-2.1-$ \\
\hline
\end{tabular}

SD — standard deviation score; * $p<0.05$; values shown are as median [range]

in 5 boys $(83 \%)$ and 11 girls (84\%). Nine patients $(47 \%)$ were on pancreatic enzyme replacement therapy during the observation period. All the patients, except for one, presented with neutropaenia. Two patients (10\%) at the age of 2 years underwent HSCT due to bone marrow failure.

\section{Endocrinologic assessment}

In the analysed cohort, 7 patients $(37 \%)$ were diagnosed with growth hormone deficiency (GHD) and had received recombinant human growth hormone $(\mathrm{rGH})$ (Tab. 3). Treatment with $\mathrm{rGH}$ was started at a median age of 8.3 years (range: $5-11$ years). Five patients are still receiving $\mathrm{rGH}$ with a good response after 2 years of therapy, while 1 patient received the treatment at around the time of puberty with a moderate response. One girl had been receiving $\mathrm{rGH}$ treatment from the age 5.5 to 14 years with a final height $-2.63 \mathrm{SD} ; \mathrm{MPH}$ $0.27 \mathrm{SD}$. The stimulated peak GH levels were $5.0 \mathrm{ng} / \mathrm{mL}$ (test with glucagon) and $7.9 \mathrm{ng} / \mathrm{mL}$ (test with clonidine) and IGF-1 level 62.1 ng/mL (range 59-297). Her height before $\mathrm{rGH}$ treatment was -3.87 SD. Additionally, 3 patients had low IGF-1 or IGFBP-3 levels, but their heights were $>-2 \mathrm{SD}$ and they did not qualify for $\mathrm{rGH}$ treatment. Sixteen patients $(84 \%)$ had delayed bone age. Their median bone age was 1.4 years (range: $0.5-2.5$ years), which was delayed for their chronological age.

The group of boys presented with a significantly lower height $(-2.1$ SD, $\mathrm{p}<0.0001)$ and BMI $(-1.0$ SD, $\mathrm{p}<0.00001)$. The group of girls also showed significantly lower height $(-2.6 \mathrm{SD}, \mathrm{p}<0.00001)$ and BMI $(-0.7$ $\mathrm{SD}, \mathrm{p}<0.0001)$. The mean mid-parental $(\mathrm{MPH})$ height was similar to the mean for the general population. Both groups presented with a significant difference between subject's height SD and MPH SD (boys -2.3 SD; girls $-2.5 \mathrm{SD})$ (Tab. 2). Fourteen patients (74\%) had a height below -2.0 SD (Tab. 3).
Table 3. Percentage of patients with Shwachman-Diamond syndrome (SDS) with abnormal endocrine status according to sex

\begin{tabular}{|c|c|c|}
\hline \multirow{2}{*}{ Patients' characteristics } & \multicolumn{2}{|c|}{ Study cohort } \\
\hline & Male & Female \\
\hline Total & 6 & 13 \\
\hline \multicolumn{3}{|l|}{$\begin{array}{l}\text { Patients with } \\
\text { endocrinopathies }\end{array}$} \\
\hline None & $1(17)$ & $6(46)$ \\
\hline One only & $4(66)$ & $5(39)$ \\
\hline Two only & $1(17)$ & $2(15)$ \\
\hline Greater than two & 0 & 0 \\
\hline $\begin{array}{l}\text { GH screen (low IGF-1 and } \\
\text { low IGFBP-3 or stimulated } \\
\mathrm{GH}<10 \text { ) }\end{array}$ & $4(66)$ & $6(46)$ \\
\hline $\mathrm{GH}$ treatment & $2(33)$ & $5(38)$ \\
\hline Hypothyroidism & $1(17)$ & $1(8)$ \\
\hline $\begin{array}{l}\text { Abnormal glucose } \\
\text { (2-h OGTT glucose }>140 \\
\mathrm{mg} / \mathrm{dL} \text { or FPG }>100 \mathrm{mg} / \mathrm{dL} \\
\left.\text { or } \mathrm{HbA}_{1 \mathrm{c}}>6.0 \%\right)\end{array}$ & $1(17)$ & 0 \\
\hline Type 1 diabetes & $1(17)$ & 0 \\
\hline Adrenal insufficiency & 0 & $1(8)$ \\
\hline $\begin{array}{l}\text { Osteopenia } \\
\text { (BMD <-1.0 T-Score) }\end{array}$ & $4(80)^{\#}$ & $8(80)^{\#}$ \\
\hline $\begin{array}{l}\text { Short stature } \\
\text { (height }<-2.0 \mathrm{SD} \text { ) }\end{array}$ & $5(83)$ & $9(69)$ \\
\hline Delayed bone age & $6(100)$ & $10(77)$ \\
\hline \multicolumn{3}{|c|}{$\begin{array}{l}\text { SD - standard deviation score; GH - growth hormone; IGF-1 - insulin-like } \\
\text { growth hormone; IGFBP- } 3 \text { - insulin-like growth factor-binding protein; } \\
\text { OGTT - oral glucose tolerance test; } F P G \text { - fasting plasma glucose; } \\
\text { T1DM - type } 1 \text { diabetes mellitus; BMD - bone mineral density. } \\
\text { Values are } n, n(\%) \text {. The percentage is given in brackets and refers to the total } \\
\text { count of male and female patients. "BMD measurements data available } \\
\text { for } 5 \text { boys and } 10 \text { girls }\end{array}$} \\
\hline
\end{tabular}

Hypothyroidism was reported in $2(10 \%)$ patients with TSH $>5 \mathrm{mU} / \mathrm{L}$ and low FT4 requiring L-thyroxin substitution. Thyroid antibodies were negative.

Fasting glucose, insulin, OGTT, C-peptide, and $\mathrm{HbA}_{1 \mathrm{c}}$ were normal, except for one patient who was on an insulin pump for T1DM. This patient had positive islet cell antibodies and a family history of SDS but no family history of T1DM.

One girl was diagnosed with congenital hypopituitarism during the diagnosis of hypoglycaemia and cholestasis at 3 months of age. The endocrinological evaluation showed adrenocorticotropin (ACTH) and $\mathrm{GH}$ deficiency; subsequently, hydrocortisone and $\mathrm{rGH}$ treatment were started.

Only 9 of the patients were of pubertal age, and they were each appropriately in puberty. One girl who underwent prior HSCT had gonadotropin elevation (FSH: $20.1 \mathrm{IU} / \mathrm{L}$, range $0.4-12.7$ ) at the age 


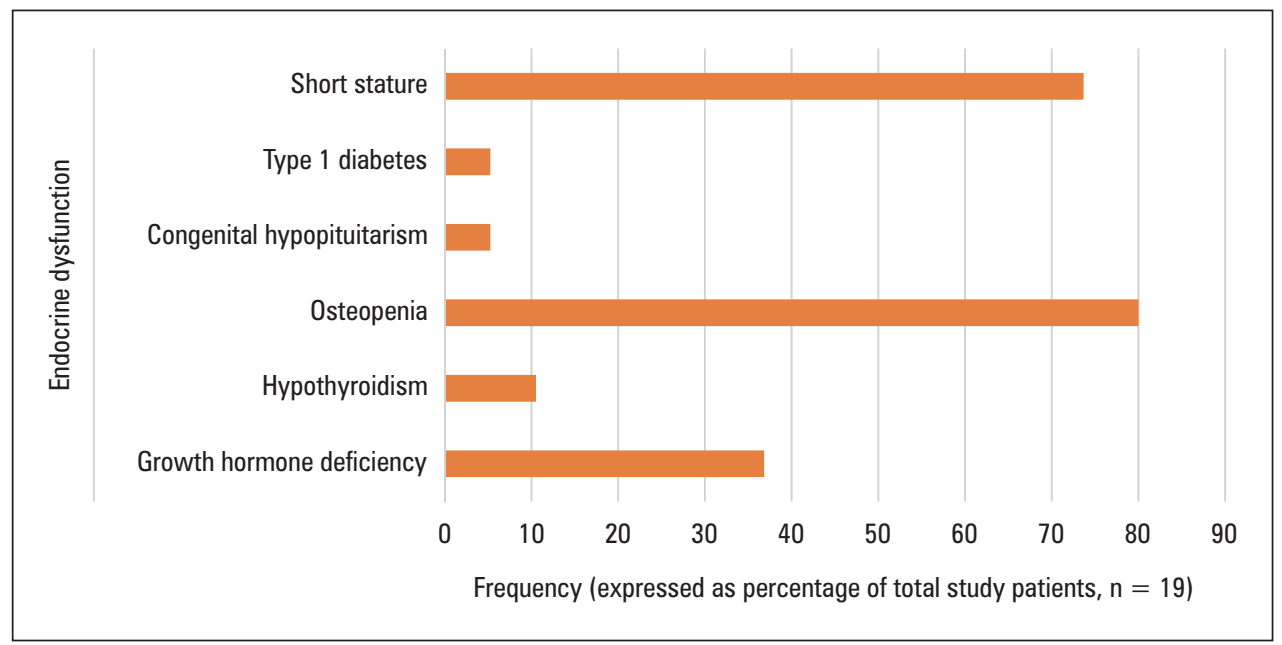

Figure 1. Endocrine and anthropometric dysfunction in patients with Shwachman-Diamond syndrome (SDS). Bar diagram showing frequencies of various endocrine and anthropometric dysfunction in our patients with SDS

of 5 years, suggestive of partial gonadal impairment after HSCT.

All 19 patients had been supplemented with vitamin D. None of the patients had severe vitamin $\mathrm{D}$ deficiency (median $32.4 \mathrm{ng} / \mathrm{mL}$, range: $22-39 \mathrm{ng} / \mathrm{mL}$ ), but 6 patients $(32 \%)$ had values consistent with hypovitaminosis. Bone mineral density results were available for 15 patients, and osteopaenia was found in 12 patients $(80 \%)$ concerning their bone age.

\section{Discussion}

Shwachman-Diamond syndrome is a rare multisystemic genetic disease with no well-defined prevalence. Our report evaluates endocrine function in a relatively large group of paediatric patients with SDS confirmed by molecular testing of the SBDS gene. We found a considerably higher incidence of endocrinopathies than previously reported $[8,21]$. In our cohort, $63 \%$ of patients had one or more endocrinopathies. In order of frequency, these included growth hormone deficiency, hypothyroidism, congenital hypopituitarism, and T1DM (Fig. 1).

Several international registries are working to better understand the phenotype of SDS and characterize the pathophysiology of this complex disorder [22]. However, the endocrine profile of SDS has not been well characterized so far. Previous studies of endocrine function in patients with SDS consist mostly of reports of small numbers of cases, with limited endocrinologic evaluations. Only one report by Myers et al. evaluated endocrine disorders in SDS, but it was a retrospective review and not all tests were performed on every patient [8]. That might explain why we found a higher incidence of endocrinopathies in our cohort.
In 2018 Cipolli et al. published the first growth charts for SDS patients from an Italian cohort of 0-8-year-olds [2].That retrospective study included 106 patients. The authors created specific charts for height, weight, and BMI for SDS children, which serve as helpful tools used in monitoring treatment efficacy and for the purposes of routine medical follow-up [2]. The frequency of short stature was similar to our findings, with $74 \%$ of patients having height below the $3^{\text {rd }}$ percentile. Although short stature and failure to thrive are not included in the diagnostic criteria of SDS, most papers $[1,2,8-10,15,23]$ and our data indicate that abnormal somatic development comprises a cardinal symptom of the syndrome. Severe growth retardation is one of the typical features, which can be said to be linked to the genetic cause of the disease [2]. It is worth emphasizing that BMI is normal in the majority of SDS patients $[2,8]$, and it should be a reference tool for assessing somatic development. The weight percentile should be always accessed with regard to growth age, instead of calendar age, which can draw conclusions inadequately. Metaphyseal chondrodysplasia, a well-known feature of SDS, may contribute to shorter stature in about one-third of patients with SDS [8]. Although, short stature in SDS should not be dismissed as simply part of the syndrome, as we identified growth hormone deficiency in 7 (37\%) of the 19 patients. Additionally, rGH treatment was reported previously in several cases [2, 8, 10, 11, 23]. Children with poor growth or slow growth velocity can benefit from an endocrinological evaluation and tests for growth hormone deficiency. The association of SDS and various malignancies, especially acute myeloid leukaemia, raises theoretical concerns about rGH safety that must be explained to the patient and 
family. Recombinant human GH treatment should by conducted to maintain serum IGF-1 in the mid-normal range for age. A retrospective report on $\mathrm{rGH}$ therapy in patients with SDS is needed to assess the efficiency and safety of rGH treatment.

Typical skeletal changes are present in all patients with SDS; however, their severity and location change with age [24]. In the cohort being the subject of analyses, all the patients had skeletal changes, but only 7 presented such abnormalities in the physical examination. The characteristic changes included delayed appearance of secondary ossification centres, metaphyseal dysostosis, and generalized osteopaenia [24]. Eighty per cent of the patients in the cohort who underwent bone mineral density measurements showed osteopaenia. According to Rosendahl et al. and Toiviainen-Salo et al., who studied bone mineral density, bone biopsies, and vitamin $\mathrm{D}$ and $\mathrm{K}$ status in SDS patients, there is a primary defect of bone metabolism in children affected with SDS [12, 25]. Vitamin D insufficiency was common in our cohort, with $32 \%$ having a $25(0 \mathrm{~h}) \mathrm{D}$ level below 30 $\mathrm{ng} / \mathrm{mL}$, despite taking supplements in all cases. Screening for bone mineral density and vitamin D level should be performed in all SDS patients. The delayed bone age assessed in $16(84 \%)$ of our SDS patients, similarly to the findings of Schaballie et al. [26], improved the prediction of their final height.

Case reports of individuals with SDS and T1DM have been described [8,12-14]. Gana et al. reported an occurrence rate of T1DM of $3.23 \%$ in 62 individuals with SBDS from the Italian registry. They noted a 30-fold increase of T1DM incidence compared to the general population [13]. In our cohort only 1 out of 19 patients $(5 \%)$ developed T1DM; comparable results were reported by Myers et al. [8].

Puberty was present in all our adolescent patients, although 1 had FSH elevation consistent with partial primary hypogonadism after HSCT.

Intrinsic limitations of our study include the relatively young median age of our patients, so bone densitometry could have been performed only in 15 older children. Further prospective studies may be warranted to validate and confirm these findings.

\section{Conclusions}

In conclusion, SDS predisposes to endocrinopathy. As many as $63 \%$ of the studied SDS patients presented with one or more endocrinopathies. Short stature appears to be associated with genotype and growth hormone deficiency rather than with malnutrition or pancreatic insufficiency. Osteopaenia is a common finding in patients affected with SDS. That is why bone density measurements and vitamin D3 plasma concen- tration should be routinely performed. We recommend monitoring of height and BMI in children with SDS, to diagnose growth failure. Additional endocrine testing should be performed if clinically indicated.

\section{Acknowledgements}

The authors want to thank all participating colleagues for recruiting patients, and the patients and their parents for participating in this study.

\section{Conflict of interest}

The authors declare that they have no conflict of interest.

\section{Funding}

This study was funded by a grant (257/18) of The Children's Memorial Health Institute, Warsaw, Poland.

\section{References}

1. Dror Y, Donadieu J, Koglmeier J, et al. Draft consensus guidelines for diagnosis and treatment of Shwachman-Diamond syndrome. Ann N Y Acad Sci. 2011; 1242: 40-55, doi: 10.1111/j.1749-6632.2011.06349.x, indexed in Pubmed: 22191555

2. Cipolli M, Tridello G, Micheletto A, et al. Italian Registry Organization. Normative growth charts for Shwachman-Diamond syndrome from Italian cohort of 0-8 years old. BMJ Open. 2019; 9(1): e022617, doi: 10.1136/bmjopen-2018-022617, indexed in Pubmed: 30782681.

3. Nelson AS, Myers KC. Diagnosis, Treatment, and Molecular Pathology of Shwachman-Diamond Syndrome. Hematol Oncol Clin North Am. 2018; 32(4): 687-700, doi: 10.1016/j.hoc.2018.04.006, indexed in Pubmed: 30047420.

4. Carapito R, Konantz M, Paillard C, et al. Mutations in signal recognition particle SRP54 cause syndromic neutropenia with Shwachman-Diamond-like features. J Clin Invest. 2017; 127(11): 4090-4103, doi: 10.1172/JCI92876, indexed in Pubmed: 28972538.

5. Dhanraj S, Matveev A, Li H, et al. Biallelic mutations in cause Shwachman-Diamond syndrome. Blood. 2017; 129(11): 1557-1562, doi: 10.1182/blood-2016-08-735431, indexed in Pubmed: 28062395.

6. Tan S, Kermasson L, Hoslin A, et al. EFL1 mutations impair eIF6 release to cause Shwachman-Diamond syndrome. Blood. 2019; 134(3): 277-290, doi: 10.1182/blood.2018893404, indexed in Pubmed: 31151987.

7. Bezzerri V, Cipolli M. Shwachman-Diamond Syndrome: Molecula Mechanisms and Current Perspectives. Mol Diagn Ther. 2019; 23(2): 281-290, doi: 10.1007/s40291-018-0368-2, indexed in Pubmed: 30413969.

8. Myers KC, Rose SR, Rutter MM, et al. Endocrine evaluation of children with and without Shwachman-Bodian-Diamond syndrome gene mutations and Shwachman-Diamond syndrome. J Pediatr. 2013, 162(6): 1235-40, 1240.e1, doi: 10.1016/j.jpeds.2012.11.062, indexed in Pubmed: 23305959.

9. Bogusz-Wójcik A, Kołodziejczyk H, Klaudel-Dreszler M, et al. Somatic development in children with Shwachman-Diamond syndrome. Ital J Pediatr. 2020; 46(1): 151, doi: 10.1186/s13052-020-00919-z, indexed in Pubmed: 33046118.

10. Delaporta P, Sofocleous C, Economou M, et al. The Greek Registry of Shwachman Diamond-Syndrome: Molecular and clinical data. Pediatr Blood Cancer. 2017; 64(11), doi: 10.1002/pbc.26630, indexed in Pubmed: 28509441

11. Goeteyn M. Ichthyosis, exocrine pancreatic insufficiency, impaired neutrophil chemotaxis, growth retardation, and metaphyseal dysplasia (Shwachman syndrome). Report of a case with extensive skin lesions (clinical, histological, and ultrastructural findings). Arch Dermatol. 1991; 127(2): 225-230, doi: 10.1001/archderm.127.2.225, indexed in Pubmed: 1990988.

12. Rosendahl J, Teich N, Mossner J, et al. Compound heterozygous mutations of the SBDS gene in a patient with Shwachman-Diamond syndrome, type 1 diabetes mellitus and osteoporosis. Pancreatology. 2006, 6(6): 549-554, doi: 10.1159/000096978, indexed in Pubmed: 17106217.

13. Gana S, Sainati L, Frau MR, et al. Shwachman-Diamond syndrome and type 1 diabetes mellitus: more than a chance association? Exp Clin Endocrinol Diabetes. 2011; 119(10): 610-612, doi: 10.1055/s-0031-1275699, indexed in Pubmed: 21553366

14. Kamoda T, Saito T, Kinugasa H, et al. A case of Shwachman-Diamond syndrome presenting with diabetes from early infancy. Diabetes 
Care. 2005; 28(6): 1508-1509, doi: 10.2337/diacare.28.6.1508, indexed in Pubmed: 15920082.

15. Myers KC, Bolyard AA, Otto B, et al. Variable clinical presentation of Shwachman-Diamond syndrome: update from the North American Shwachman-Diamond Syndrome Registry. J Pediatr. 2014; 164(4): 866-870, doi: 10.1016/j.jpeds.2013.11.039, indexed in Pubmed: 24388329.

16. Jivani N, Torrado-Jule $C$, Vaiselbuh $S$, et al. A unique case of Shwachman-Diamond syndrome presenting with congenital hypopituitarism. J Pediatr Endocrinol Metab. 2016; 29(11): 1325-1327, doi: 10.1515/jpem-2016-0299, indexed in Pubmed: 27754968.

17. Palczewska I. Indicators of the somatic development of Warsaw children and youth. Dev Period Med. 2001; 5(1): 17-118.

18. Holick MF, Binkley NC, Bischoff-Ferrari HA, et al. Endocrine Society. Evaluation, treatment, and prevention of vitamin D deficiency: an Endocrine Society clinical practice guideline. J Clin Endocrinol Metab. 2011; 96(7): 1911-1930, doi: 10.1210/jc.2011-0385, indexed in Pubmed: 21646368.

19. Wejnarska K, Kołodziejczyk E, Ryżko J, et al. Comparison of 72-hour fecal fat quantification and the 13C-mixed triglyceride breath test in assessing pancreatic exocrine sufficiency in children with chronic pancreatitis. Dev Period Med. 2016; 20(3): 222-227, indexed in Pubmed: 27941193.

20. Genant HK, Cooper C, Poor G, et al. Interim report and recommendations of the World Health Organization Task-Force for Osteoporosis. Osteoporos Int. 1999; 10(4): 259-264, doi: 10.1007/s001980050224, indexed in Pubmed: 10692972
21. Myers KC, Bolyard AA, Otto B, et al. Variable clinical presentation of Shwachman-Diamond syndrome: update from the North American Shwachman-Diamond Syndrome Registry. J Pediatr. 2014; 164(4) 866-870, doi: 10.1016/j.jpeds.2013.11.039, indexed in Pubmed: 24388329.

22. Furutani E, Shah AS, Zhao Y, et al. Inflammatory manifestations in patients with Shwachman-Diamond syndrome: A novel phenotype. Am J Med Genet A. 2020; 182(7): 1754-1760, doi: 10.1002/ajmg.a.61593, indexed in Pubmed: 32293785.

23. Kornfeld SJ, Kratz J, Diamond F, et al. Shwachman-Diamond syndrome associated with hypogammaglobulinemia and growth hormone deficiency. J Allergy Clin Immunol. 1995; 96(2): 247-250, doi: 10.1016/s0091-6749(95)70014-5, indexed in Pubmed: 7636061.

24. Mäkitie O, Ellis L, Durie PR, et al. Skeletal phenotype in patients with Shwachman-Diamond syndrome and mutations in SBDS. Clin Genet. 2004; 65(2): 101-112, doi: 10.1111/j.0009-9163.2004.00198.x, indexed in Pubmed: 14984468 .

25. Toiviainen-Salo S, Mäyränpää MK, Durie PR, et al. Shwachman-Diamond syndrome is associated with low-turnover osteoporosis. Bone. 2007; 41(6): 965-972, doi: 10.1016/j.bone.2007.08.035, indexed in Pubmed: 17920346.

26. Schaballie $\mathrm{H}$, Renard M, Vermylen $\mathrm{C}$, et al. Misdiagnosis as asphyxiating thoracic dystrophy and CMV-associated haemophagocytic lymphohistiocytosis in Shwachman-Diamond syndrome. Eur J Pediatr. 2013; 172(5): 613-622, doi: 10.1007/s00431-012-1908-0, indexed in Pubmed: 23315050. 